\title{
Druckfehlerberichtigung zu:
}

Walther J. Otis, Die Morphogenese und Histogenese des Analhöckers nebst Beobachtungen über die Entwickelung des Sphincter ani externus beim Menschen. Heft 90 (30. Bd., H. 1.)

Man lese: 'Seite 213 Zeile 6 von oben des Urethralkanales statt der Urethralspalte.

- $215,14, \quad$ rechte statt letzte.

, 220,16 , unten Kloakenplatte statt Kloakenspalte.

- $223,4, \quad$ Zellen der Platte selbst statt Zellen selbst.

" $226,14, \quad$, Entoderm statt Ektoderm.

" $232,-9, "$ " Schnitten statt Schritten.

, $237,6,-$ deswegen der Mangel statt wegen des Mangels.

Endlich ist: , $244,2, \quad, \quad$ der Beistrich vor, statt nach ist $\mathbf{z u}$ setzen und

, 258,1 , oben ano-génitale statt urogénitale zu lesen. 